\section{OPEN ACCESS}

Edited by:

Adolfo Andrade-Cetto,

National Autonomous University

of Mexico (UNAM), Mexico

Reviewed by:

Somiranjan Ghosh,

Howard University, USA

Bey Hing Goh,

Monash University Malaysia, Malaysia

${ }^{*}$ Correspondence:

Johannes Van Staden rcpgd@ukzn.ac.za

Specialty section:

This article was submitted to

Ethnopharmacology,

a section of the journal

Frontiers in Pharmacology

Received: 08 July 2016 Accepted: 09 September 2016 Published: 03 October 2016

Citation:

Baskaran P, Kumari A, Ncube B and

Van Staden J (2016)

Acetylcholinesterase-Inhibition and Antibacterial Activity of Mondia whitei Adventitious Roots and Ex vitro-Grown Somatic

Embryogenic-Biomass.

Front. Pharmacol. 7:335 doi: 10.3389/fphar.2016.00335

\title{
Acetylcholinesterase-Inhibition and Antibacterial Activity of Mondia whitei Adventitious Roots and Ex vitro-Grown Somatic Embryogenic-Biomass
}

Ponnusamy Baskaran, Aloka Kumari, Bhekumthetho Ncube and Johannes Van Staden*

Research Centre for Plant Growth and Development, School of Life Sciences, University of KwaZulu-Natal, Pietermaritzburg, South Africa

Mondia whitei (Hook.f.) Skeels is an important endangered medicinal and commercial plant in South Africa. In vitro propagation systems are required for biomass production and bioactivity analysis to supplement wild resources/stocks. Adventitious roots from somatic embryogenic explants using suspension culture and ex vitro-grown plants produced via somatic embryogenesis were established using different plant growth regulator treatments. The adventitious root biomass and different parts of ex vitro-grown and mother plants were used to investigate the potential for acetylcholinesterase (AChE) and antibacterial activities. Adventitious roots derived from $2.5 \mu \mathrm{M}$ indole-3-acetic acid (IAA) treatments and ex vitro-grown plants derived from meta-topolin riboside and IAA treatments gave the best AChE and antibacterial activities. The in vitro-established M. whitei and ex vitro biomass have comparable ability to function as inhibitors of acetylcholinesterase and antibacterial agents, and can be used as potent bioresources in traditional medicine.

Keywords: acetylcholinesterase-inhibition, adventitious root, bioactivity, medicinal plant, somatic embryogenesis

\section{INTRODUCTION}

Mondia whitei (Hook.f.) Skeels is an important endangered medicinal plant included in the Red Data List of South African plants as a result of its over-exploitation for various medicinal uses (SANBI, 2013; Baskaran et al., 2015; Van Wyk, 2015). The conservation status and medicinal importance requires the development of an efficient mass propagation system. The plant's root is used in the treatment of various diseases including those related to nervous conditions (Gelfand et al., 1985; Noumi et al., 1998; Oketch-Rabah, 2012; Baskaran et al., 2015; Van Wyk, 2015). Accordingly, assay of acetylcholinesterase (AChE: primary cholinesterase enzyme for nerve agents) and antibacterial properties for numerous clinical problems caused by bacteria needs to be examined in $M$. whitei. The in vitro established micropropagated plants requires evaluation for bioactivity to ascertain if the medicinal properties remains unchanged (Nagarajan et al., 2011; García-Pérez et al., 2012; Baskaran et al., 2014). Many bacterial strains (for example, Enterococcus faecalis) are becoming 
resistant to antibiotics; therefore, the search for potent medicinal plants represent a natural source that requires exploration. Furthermore, the application of biotechnological techniques has permitted harvesting and evaluation of in vitro regenerated plants and plant materials at various stages of plant growth and development (Nagarajan et al., 2011; García-Pérez et al., 2012; El-Bakry et al., 2014). A report of in vitro adventitious root culture and ex vitro-grown plants derived from somatic embryogenesis are required to test the bioactivity to support and utilization in medicinal systems as well as to preserve existing M. whitei populations. Establishing adventitious roots by suspension culture and ex vitro-grown plants from somatic embryogenetic origin would accelerate large-scale biomass and conservation in addition to supplementing pharmaceutical products to study the biological significance of the species bioactivity (Cui et al., 2010; Ho et al., 2013; Baskaran et al., 2014).

In vitro culture developed plant biomass has found pharmacological applications worldwide (García-Pérez et al., 2012; Ho et al., 2013). Acetylcholinesterase (AChE: primary cholinesterase enzyme) functions as a neurotransmitter and the assay of AChE activity plays an important role in diagnostic, nerve agents, in vitro characterization of toxins and drugs, including potential treatments for Alzheimer's disease (Pohanka et al., 2011). Numerous bacterial diseases, including diarrhea, can be alleviated by extracts from various parts of in vitro and ex vitro-grown plants (Nagarajan et al., 2011; García-Pérez et al., 2012). The aim of this study therefore, was to develop a simple and efficient protocol for the production of adventitious roots using somatic embryogenic explants in suspension culture and to examine the AChE and antibacterial activities from the biomass of the adventitious roots and different parts of ex vitro-grown plants derived via somatic embryogenesis, using the mother plant for comparison. The hormonal effects of the adventitious root and somatic embryogenesis-derived ex vitro plants of $M$. whitei biomass on AChE-inhibition and antibacterial activities were also determined.

\section{MATERIALS AND METHODS}

\section{Production of Adventitious Roots in Suspension Culture}

Torpedo stage somatic embryos (SEs) of M. whitei were collected using a previously described somatic embryogenesis protocol (Baskaran et al., 2015) on solid ( $8 \mathrm{~g} \mathrm{~L}^{-1}$ agar) MS (Murashige and Skoog, 1962) medium with $40 \mathrm{~g} \mathrm{~L}^{-1}$ sucrose, $20 \mu \mathrm{M}$ 2,4$\mathrm{D}$, and $1 \mu \mathrm{M}$ TDZ. The embryos (approximately $7-10$ ) were transferred to $250 \mathrm{~mL}$ Erlenmeyer flasks containing $50 \mathrm{~mL}$ liquid MS medium with $30 \mathrm{~g} \mathrm{~L}^{-1}$ sucrose for induction of roots for 4 weeks. The roots ( $1 \mathrm{~g} \mathrm{~L}^{-1}, 3-5 \mathrm{~cm}$ long) were transferred to $50 \mathrm{~mL}$ liquid MS medium containing $30 \mathrm{~g} \mathrm{~L}^{-1}$ sucrose plus $2.5-10 \mu \mathrm{M}$ indole-3-acetic acid (IAA) or indole-3-butyric acid (IBA) and $2.5-15 \mu \mathrm{M}$ naphthaleneacetic acid (NAA) in a $250 \mathrm{~mL}$ Erlenmeyer flask to optimize a concentration of auxin for enhancement of adventitious root biomass for 8 weeks. The liquid cultures were maintained on an orbital shaker at $100 \mathrm{rpm}$ at $25 \pm 2{ }^{\circ} \mathrm{C}$ and light intensity of $40 \mu \mathrm{mol} \mathrm{m} \mathrm{m}^{-2} \mathrm{~s}^{-1}$ provided by cool white fluorescent light (OSRAM L 58 W/740, South Africa) with a $16 \mathrm{~h}$ photoperiod. All experiments were conducted three times with five replicates per treatment. In all experiments, medium lacking plant growth regulators served as controls. The chemicals used were of analytical grade (Biolab, South Africa; Oxoid, England and Sigma, USA). All media were adjusted to $\mathrm{pH}$ 5.8 with $0.1 \mathrm{~N} \mathrm{NaOH}$ and/or $0.1 \mathrm{~N} \mathrm{HCl}$ and autoclaved at $121^{\circ} \mathrm{C}$ for $20 \mathrm{~min}$.

Roots were filtered through sieves $(200 \mu \mathrm{m})$, and the fresh weight (FW) measured after rinsing once with sterile distilled water and blotting away the surface water. The roots were dried at $50^{\circ} \mathrm{C}$ for 1 day, and the root dry weight (DW) was recorded. Adventitious root growth ratio was calculated as harvested DW (g) - inoculated DW (g)/inoculated DW (g). The data were statistically analyzed for analysis of variance (ANOVA), and are presented as mean \pm standard error of three independent experiments. Treatment means were separated using Duncan's multiple range test at 5\% probability level. All statistical analysis was done using SPSS for Windows version 23 (SPSS Inc., Chicago, IL, USA).

\section{Ex vitro Plants from Somatic Embryogenesis}

The 18-month-old somatic embryogenesis system produced (Baskaran et al., 2015) ex vitro-grown plants of $M$. whitei derived from different treatments $\left[50 \mathrm{~g} \mathrm{~L}^{-1}\right.$ sucrose $+20 \mu \mathrm{M} 2,4$ dichlorophenoxy acetic acid (2,4-D), $40 \mathrm{~g} \mathrm{~L}^{-1}$ sucrose $+20 \mu \mathrm{M}$ $2,4-\mathrm{D}+1 \mu \mathrm{M}$ thidiazuron (TDZ), $35 \mathrm{~g} \mathrm{~L}^{-1}$ sucrose $+20 \mu \mathrm{M}$ picloram $+1 \mu \mathrm{M}$ benzyladenine (BA), $20 \mathrm{~g} \mathrm{~L}^{-1}$ sucrose + $0.5 \mu \mathrm{M}$ meta-topolin riboside $(m \mathrm{TR})+0.25 \mu \mathrm{M}$ IAA and $20 \mathrm{~g}$ $\mathrm{L}^{-1}$ sucrose $+0.5 \mu \mathrm{M}$ kinetin $(\mathrm{Kin})+0.25 \mu \mathrm{M}$ IAA; Tables 1 and 2] were used for the bioassay studies.

Different plant materials (root, leaf, and stem) were harvested from ex vitro-grown [1:1 (v/v) vermiculite:soil mixture under greenhouse conditions $\left(25 \pm 2{ }^{\circ} \mathrm{C}\right.$ under natural photoperiod conditions and a midday PPF of $\left.\left.950 \pm 50 \mu \mathrm{mol} \mathrm{m}^{-2} \mathrm{~s}^{-1}\right)\right]$ and mother plant (15-years-old) at the same time period (to avoid seasonal differences), washed thoroughly with sterile water and dried in an oven set at $50^{\circ} \mathrm{C}$ in the dark.

\section{Bioactivity Studies}

The oven-dried plant materials (ex vitro-grown, mother plant and adventitious root: $1 \mathrm{~g}$ powder each) were extracted with $70 \%$ $(\mathrm{v} / \mathrm{v})$ methanol $(100 \mathrm{~mL})$ using a sonication bath for $1 \mathrm{~h}$. The extracts were filtered through a Büchner funnel using Whatman no. 1 filter paper and the solvent evaporated under reduced pressure at $30^{\circ} \mathrm{C}$. Dried extracts were kept at $4^{\circ} \mathrm{C}$ until use. Each extract was tested for acetylcholinesterase (AChE) inhibitory and antibacterial properties. The bioactivity studies from in vitro, ex vitro, and mother plant materials of $M$. whitei are described by a schematic diagram (Figure 1).

\section{AChE-Inhibitory Assay}

The colorimetric method of Ellman et al. (1961) using a 96-well microplate as described by Fawole et al. (2010) was used. Each sample was evaluated in triplicate. Galantamine was used as a 
TABLE 1 | Acetylcholinesterase-inhibition in adventitious roots and various plant parts of ex vitro and garden-grown mother plants of Mondia whitei.

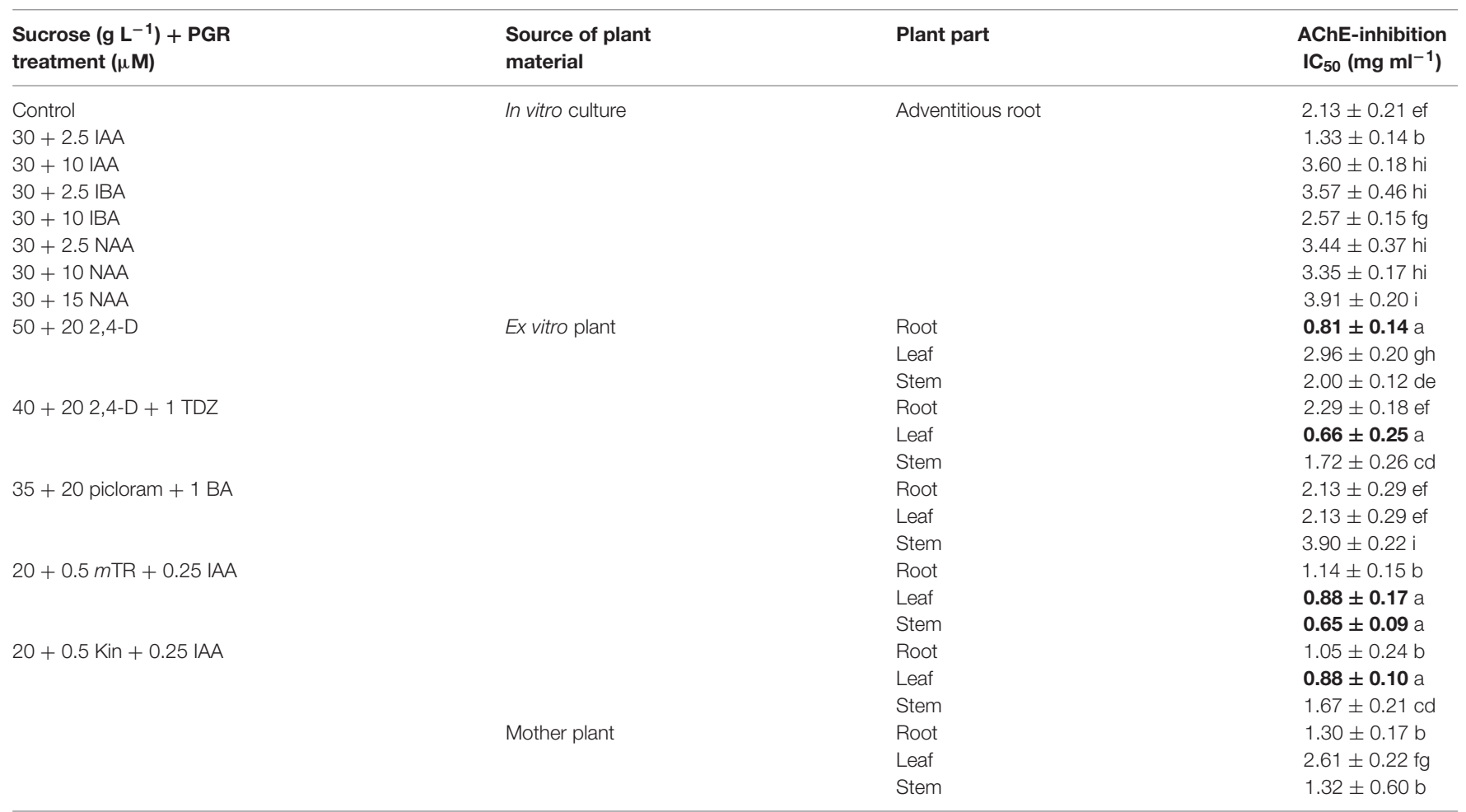

PGR, Plant growth regulator. $1 C_{50}$ for galantamine (positive control) $=1.56 \pm 0.18 \mu \mathrm{M}$. Values in bold font are considered significantly higher AChE-inhibitory activity. Results are mean \pm standard error $(n=3)$. Means followed by same letters in each column are not significantly different $(P=0.05)$ using Duncan's multiple range test.

positive control. Following the calculation of the rate of reaction for each sample, galantamine or blank, the percentage inhibition was calculated using the formula: AChE inhibition (\%) $=[1-$ (sample reaction rate/blank reaction rate) $\times 100$. A non-linear regression analysis was done using GraphPad Prism (version 4.03) software for the determination of the $\mathrm{IC}_{50}$ values. Data were subjected to analysis of variance (SPSS, version 23.0), and significant mean values were further separated using Duncan's multiple range test.

\section{Antibacterial Assay}

The microtiter bioassay (Eloff, 1998) was used to determine antibacterial activity. Extracts were tested against Gram-positive bacteria (Bacillus subtilis [ATCC 6051], E. faecalis [ATCC 19433], Micrococcus luteus [ATCC 4698], and Staphylococcus aureus [ATCC 12600]) and Gram-negative bacteria (Escherichia coli [ATCC 11775] and Klebsiella pneumoniae [ATCC 13883]). A positive control, neomycin $\left(\mu \mathrm{g} \mathrm{ml}^{-1}\right.$ in the first well) was used against each bacterial strain. Each determination was done in duplicate, and the assay was repeated twice.

\section{RESULTS AND DISCUSSION}

\section{Production of Adventitious Roots}

Root induction was achieved using the torpedo-stage somatic embryo explants in liquid MS medium containing $30 \mathrm{~g} \mathrm{~L}^{-1}$ sucrose after 4 weeks (Figures 2A,B). The adventitious roots were established from root explants cultured in liquid MS medium containing $30 \mathrm{~g} \mathrm{~L}^{-1}$ sucrose and various concentrations of auxins (IAA, IBA, and NAA; Figure 2C). Normal adventitious roots form, but require auxins in vitro (Baskaran and Jayabalan, 2009; Cui et al., 2010; El-Bakry et al., 2014; Steffens and Rusmussen, 2016). Increased concentrations $(>2.5 \mu \mathrm{M})$ of auxins improved biomass production ( $>6.79$ g/flask FW and $>2.00 \mathrm{~g} /$ flask DW; Figures 2D and 3), and the highest production of biomass (20.34 g/flask FW and $4.37 \mathrm{~g} /$ flask DW) as well as a good growth ratio was observed on medium containing $10 \mu \mathrm{M}$ NAA (Figures 2E and 3). The biomass production was markedly suppressed with an increased concentration $(15 \mu \mathrm{M})$ of NAA (Figure 3). High auxin levels are often suppressors for adventitious root growth and production of biomass (Baskaran and Jayabalan, 2009; Cui et al., 2010). In this study, the growth ratio was lower in control, $2.5 \mu \mathrm{M}$ IAA and $15 \mu \mathrm{M}$ NAA (Figure 3). These results indicate that the type of auxin and its concentration is important for growth of adventitious roots and biomass production and were in accordance with other previous reports (Baskaran and Jayabalan, 2009; El-Bakry et al., 2014).

\section{AChE-Inhibitory and Antibacterial Activities}

In this study, AChE-inhibitory activity was observed in adventitious roots, different plant parts of ex vitro-grown plants (Figures 2F,G) and the mother plant of M. whitei (Table 1). 
TABLE 2 | Antibacterial activity of adventitious roots and various plant parts of ex vitro and garden-grown mother plants of $M$. whitei.

\begin{tabular}{|c|c|c|c|c|c|c|c|c|}
\hline \multirow{2}{*}{$\begin{array}{l}\text { Sucrose }\left(\mathrm{g} \mathrm{L}^{-1}\right)+\text { PGR } \\
\text { treatment }(\mu \mathrm{M})\end{array}$} & \multirow{2}{*}{$\begin{array}{l}\text { Source of plant } \\
\text { material }\end{array}$} & \multirow[t]{2}{*}{ Plant part } & \multicolumn{6}{|c|}{ Minimum inhibitory concentration $\left(\mathrm{mg} \mathrm{ml}^{-1}\right)$} \\
\hline & & & B.s +ve & E.f + ve & $M . I^{+\mathrm{ve}}$ & S.a + ve & $E . c^{-v e}$ & $K . p^{-v e}$ \\
\hline Control & In vitro culture & Adventitious & 0.39 & 3.125 & 1.56 & 3.125 & 3.125 & 0.78 \\
\hline $30+2.5 \mathrm{IAA}$ & & root & 0.195 & 3.125 & 0.39 & 1.56 & 1.56 & 0.39 \\
\hline $30+10$ IAA & & & 0.39 & 1.56 & 0.39 & 1.56 & 1.56 & 0.39 \\
\hline $30+2.5$ IBA & & & 0.39 & 1.56 & 0.39 & 1.56 & 3.125 & 1.56 \\
\hline $30+10$ IBA & & & 0.195 & 1.56 & 0.39 & 1.56 & 1.56 & 1.56 \\
\hline $30+2.5 \mathrm{NAA}$ & & & 3.125 & 3.125 & 3.125 & 3.125 & 3.125 & 1.56 \\
\hline $30+10$ NAA & & & 0.39 & 3.125 & 1.56 & 1.56 & 1.56 & 1.56 \\
\hline $30+15$ NAA & & & 0.39 & 1.56 & 1.56 & 1.56 & 0.39 & 0.39 \\
\hline \multirow[t]{3}{*}{$50+202,4-D$} & Ex vitro plant & Root & 0.098 & 1.56 & 3.125 & 1.56 & 3.125 & 1.56 \\
\hline & & Leaf & 1.56 & 0.195 & 3.125 & 6.25 & 3.125 & 3.125 \\
\hline & & Stem & 0.098 & 0.195 & 3.125 & 6.25 & 3.125 & 3.125 \\
\hline \multirow[t]{3}{*}{$40+202,4-D+1$ TDZ } & & Root & 0.098 & 1.56 & 3.125 & 12.5 & 6.25 & 6.25 \\
\hline & & Leaf & 1.56 & 0.098 & 3.125 & 12.5 & 3.125 & 6.25 \\
\hline & & Stem & 0.098 & 0.195 & 3.125 & 12.5 & 6.25 & 3.125 \\
\hline \multirow[t]{3}{*}{$35+20 \mathrm{Pic}+1 \mathrm{BA}$} & & Root & 0.098 & 0.195 & 3.125 & 12.5 & 6.25 & 3.125 \\
\hline & & Leaf & 1.56 & 0.098 & 3.125 & 12.5 & 6.25 & 3.125 \\
\hline & & Stem & 0.098 & 0.098 & 1.56 & 12.5 & 6.25 & 3.125 \\
\hline \multirow[t]{3}{*}{$20+0.5 m T R+0.25 \mathrm{IAA}$} & & Root & 0.39 & 0.39 & 1.56 & 12.5 & 1.56 & 1.56 \\
\hline & & Leaf & 0.195 & 0.098 & 3.125 & 12.5 & 3.125 & 1.56 \\
\hline & & Stem & 0.098 & 0.098 & 3.125 & 6.25 & 3.125 & 1.56 \\
\hline \multirow[t]{6}{*}{$20+0.5 \mathrm{Kin}+0.25 \mathrm{IAA}$} & & Root & 0.098 & 1.56 & 3.125 & 6.25 & 3.125 & 3.125 \\
\hline & & Leaf & 1.56 & 0.098 & 0.78 & 12.5 & 1.56 & 1.56 \\
\hline & & Stem & 0.098 & 0.195 & 3.125 & 12.5 & 1.56 & 1.56 \\
\hline & Mother plant & Root & 0.098 & 3.125 & 1.56 & 6.25 & 3.125 & 6.25 \\
\hline & & Leaf & 0.39 & 0.78 & 0.78 & 6.25 & 0.78 & 0.78 \\
\hline & & Stem & 0.098 & 0.098 & 3.125 & 3.125 & 3.125 & 3.125 \\
\hline Neomycin (positive control) & & - & 0.024 & 0.012 & 0.0061 & 0.0061 & 0.0015 & 0.0061 \\
\hline
\end{tabular}

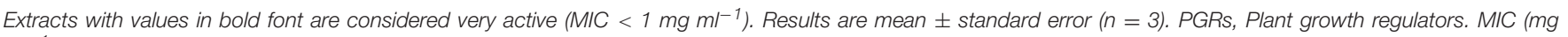
$\mathrm{ml}^{-1}$ ); B.s, Bacillus subtilis; E.f, Enterococcus faecalis; M.I, Micrococcus luteus; S.a, Staphylococcus aureus; E.c, Escherichia coli; K.p, Klebsiella pneumoniae.

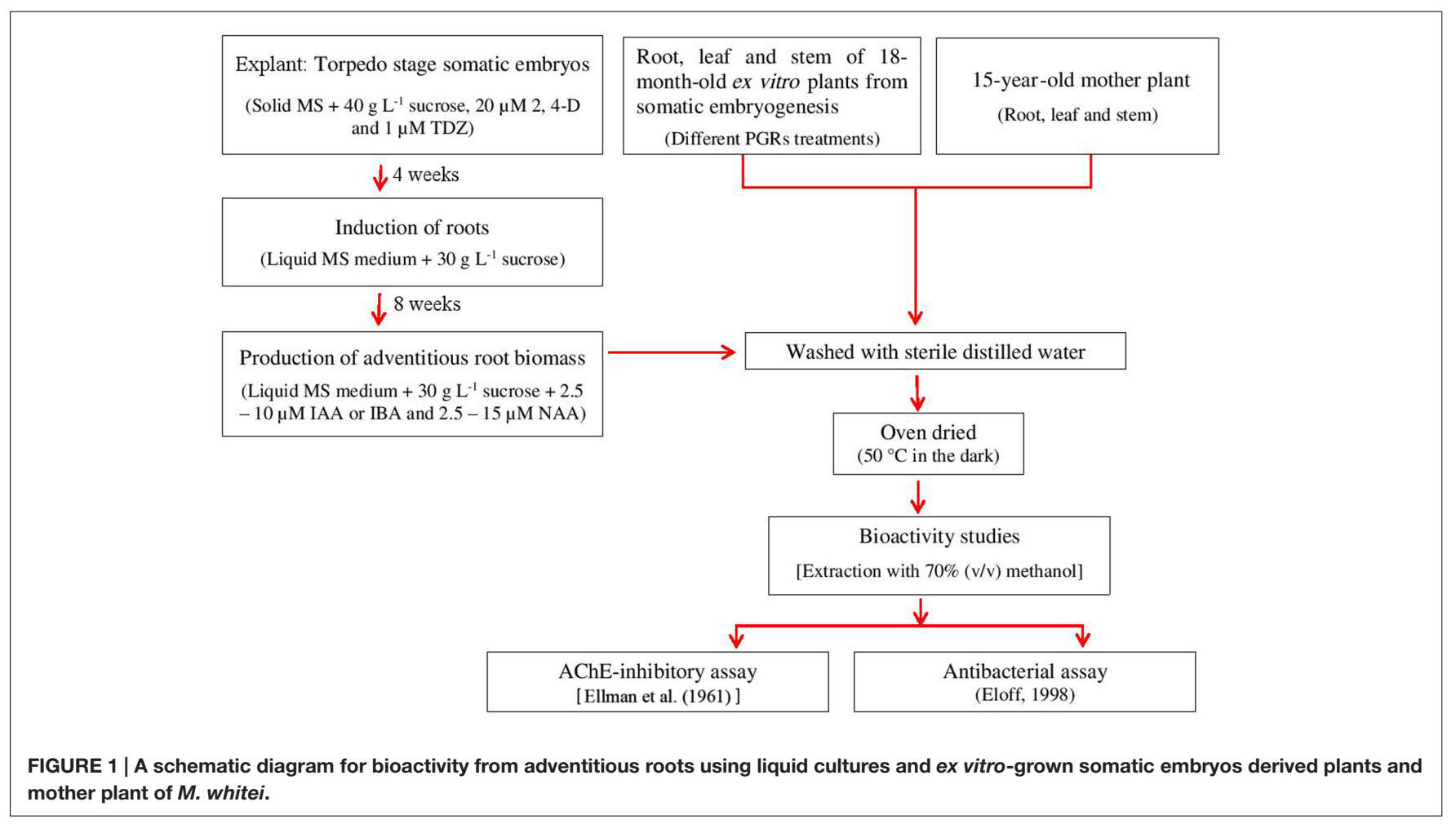




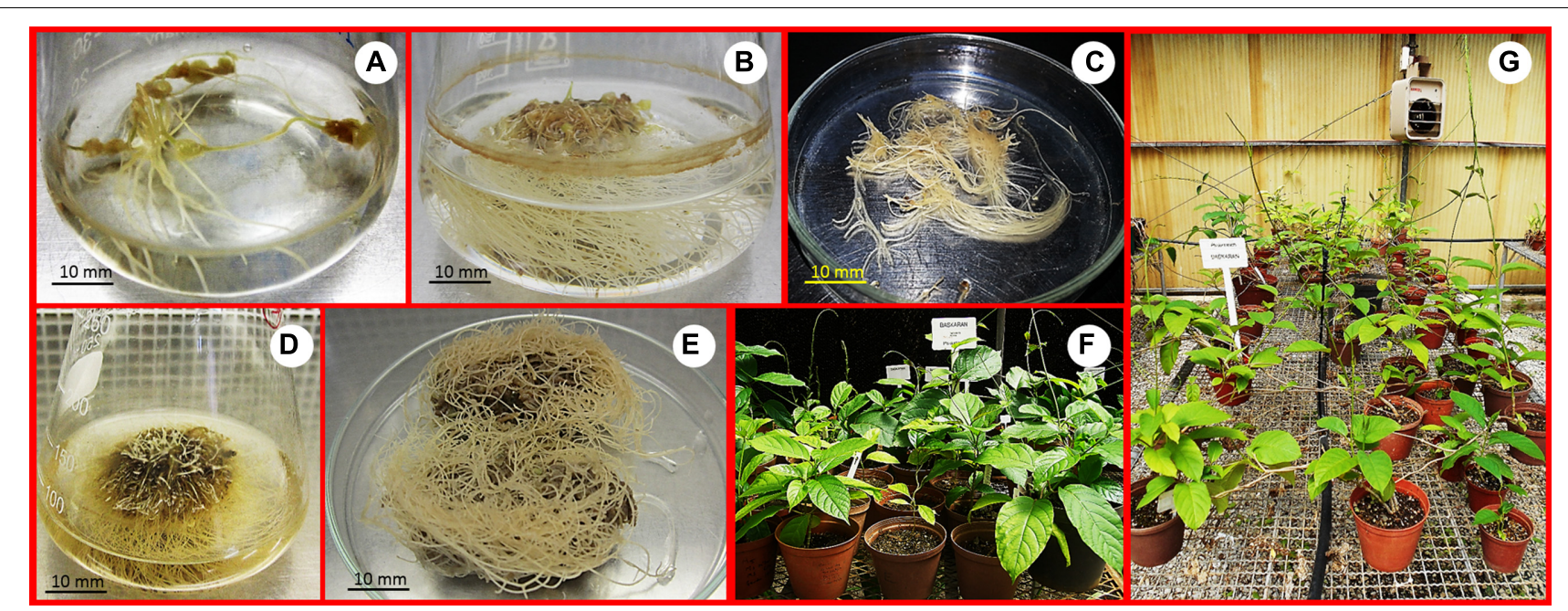

FIGURE 2 | Production of adventitious roots using liquid cultures and ex vitro-grown somatic embryos derived plants of $\boldsymbol{M}$. whitei. (A) Root induction from torpedo-stage somatic embryo explants after 2 weeks culture. (B) Root induction after 4 weeks culture. (C) Root explants for adventitious root culture. (D) Production of adventitious roots in $10 \mu \mathrm{M}$ IAA after 8 weeks culture. (E) Adventitious roots in $10 \mu \mathrm{M}$ NAA. (F) Establishment of ex vitro-grown plants in the greenhouse. (G) Ex vitro-grown plants after 18 months.

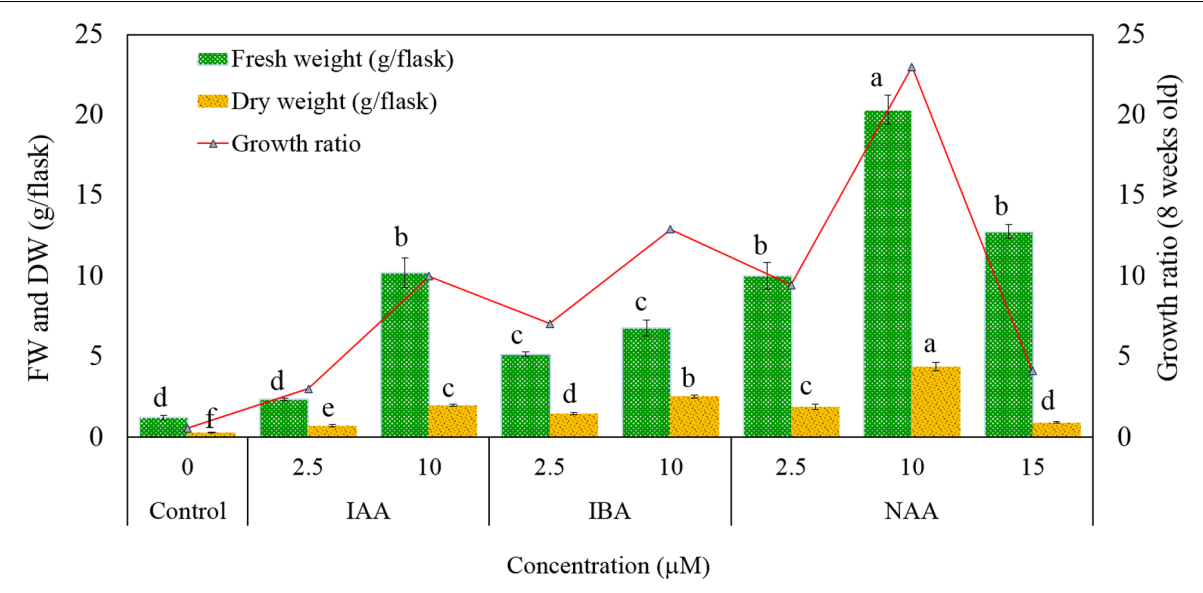

FIGURE 3 | Different concentrations of auxins for adventitious root growth [fresh weight (FW) and dry weight (DW)] and growth ratio of $M$. whitei. Results are mean \pm standard error $(n=3)$. The bar containing different letters in graph indicates significant differences at $P=0.05$ of significance using Duncan's multiple range test.

The root and stem of mother plant exhibited significant AChE-inhibitory activity, but this did not differ significantly with those of the adventitious roots $(2.5 \mu \mathrm{M}$ IAA) and roots of ex vitro-grown plants from $20 \mathrm{~g} \mathrm{~L}^{-1}$ sucrose $+0.5 \mu \mathrm{M}$ $m \mathrm{TR}+0.25 \mu \mathrm{M}$ IAA and $20 \mathrm{~g} \mathrm{~L}^{-1}$ sucrose $+0.5 \mu \mathrm{M}$ Kin $+0.25 \mu \mathrm{M}$ IAA treatments, respectively (Table 1 ). The $\mathrm{IC}_{50}$ values recorded in extracts of adventitious roots derived from control, IAA $(10 \mu \mathrm{M})$, IBA, and NAA treatments and roots, leaves and stems of ex vitro-grown plants derived from $35 \mathrm{~g}$ $\mathrm{L}^{-1}$ sucrose $+20 \mu \mathrm{M}$ picloram $+1 \mu \mathrm{M}$ BA treatments did not exhibit good AChE-inhibitory activity (Table 1). The inhibitory activity was significantly higher in roots $(50+202,4-\mathrm{D})$, leaves (40 $\mathrm{g} \mathrm{L}^{-1}$ sucrose $+202,4-\mathrm{D}+1 \mathrm{TDZ} ; 20 \mathrm{~g} \mathrm{~L}^{-1}$ sucrose $+0.5 m \mathrm{TR}+0.25 \mathrm{IAA} ; 20 \mathrm{~g} \mathrm{~L}^{-1}$ sucrose $+0.5 \mathrm{Kin}+0.25$
IAA) and stems $\left(20 \mathrm{~g} \mathrm{~L}^{-1}\right.$ sucrose $+0.5 \mathrm{mTR}+0.25$ IAA) of ex vitro plants (Table 1). Overall, AChE-inhibitory activity was good in all parts of ex vitro-grown plants derived from $20 \mathrm{~g} \mathrm{~L}^{-1}$ sucrose $+0.5 \mathrm{mTR}+0.25$ IAA treatments (Table 1). These results indicate that the AChE-inhibitory activity differs within the treatments and plant parts. The superior inhibitory effects demonstrated by IAA and $m$ TR treatments suggest that they may be regulating certain secondary compounds during in vitro and ex vitro processes. Moreover, adventitious roots and ex vitro-grown plants treated with specific PGRs in different concentrations could be an efficient substitute for improving wild populations. In addition, the therapeutic potential of ex vitro plants may influence somatic embryogenic phases. Ex vitro-grown and in vitro regenerated plants 
with PGR treatments have been reported with potential bioactivity in other plant species (Baskaran et al., 2014).

Antibacterial activity from adventitious roots and different parts of ex vitro and mother plants of $M$. whitei showed antibacterial activity against tested human pathogenic bacteria (Table 2). The bioactivity test in in vitro established tissues has been reported to support plants used in traditional medicine and prevent loss of wild populations (Baskaran et al., 2014). Extracts of adventitious roots showed good activity against both Gram-positive (B. subtilis and M. luteus) and Gram-negative (E. coli and K. pneumoniae) bacteria; however, no bioactivity was observed for adventitious roots against Gram-positive (E. faecalis and S. aureus) bacteria (Table 2). Active secondary metabolism has been reported in adventitious roots of ginseng (Yu et al., 2000; Hahn et al., 2003). The higher bioactivity was recorded in extracts of different parts of ex vitro-grown plants derived from different treatments and were more potent against B. subtilis and E. faecalis bacteria (Table 2). On the other hand, none of the extracts of the ex vitro-grown and mother plants exhibited activity against both Gram-positive (M. luteus and S. aureus) and Gram-negative (E. coli and K. pneumoniae) bacteria (Table 2). The results of this study indicate that the antibacterial activity depended on the source of plant material, tissue type and concentration of PGRs in the treatments and are in accordance with results obtained with Agapanthus praecox (Baskaran et al., 2014). Accumulation of secondary compounds as regulated by PGRs during in vitro and ex vitro-growth processes may have affected the bioactivity. However, the biochemical mechanisms surrounding these still needs to be investigated in the plant species. The results of the present study suggest that in vitro and ex vitro-grown plant parts as obtained with specific PGR treatments can effectively

\section{REFERENCES}

Baskaran, P., Chukwujekwu, J. C., Amoo, S. O., and Van Staden, J. (2014). Anticholinesterase and mutagenic evaluation of in vitro-regenerated Agapanthus praecox grown ex vitro. In Vitro Cell. Dev. Biol. Plant 50, 271-275. doi: $10.1007 /$ s11627-013-9567-z

Baskaran, P., and Jayabalan, N. (2009). Psoralen production in hairy roots and adventitious roots cultures of Psoralea corylifolia. Biotechnol. Lett. 31, 1073 1077. doi: 10.1007/s10529-009-9957-9

Baskaran, P., Kumari, A., and Van Staden, J. (2015). Embryogenesis and synthetic seed production in Mondia whitei. Plant Cell Tissue Organ Cult. 121, 205-214. doi: 10.1007/s11240-014-0695-X

Cui, X. H., Chakrabarty, D., Lee, E. J., and Paek, K. Y. (2010). Production of adventitious roots and secondary metabolites by Hypericum perforatum L. in a bioreactor. Bioresour. Technol. 101, 4708-4716. doi: 10.1016/j.biortech.2010.01.115

El-Bakry, A. A., Mostafa, H. A. M., and Alam Eman, A. (2014). Antioxidant and antibacterial activity of callus and adventitious root extracts from Rumex vesicarius L. J. Med. Plant Res. 8, 479-488. doi: 10.5897/JMPR12.846

Ellman, G. L., Coutney, D., Andies, V., and Featherstone, R. M. A. (1961). New and rapid colourimetric determination of acetylcholinesterase activity. Biochem. Pharmacol. 7, 88-95. doi: 10.1016/0006-2952(61)90145-9

Eloff, J. N. A. (1998). Sensitive and quick microplate method to determine the minimal inhibitory concentration of plant extracts for bacteria. Planta Med. 29, $129-132$.

Fawole, O. A., Amoo, S. O., Ndhlala, A. R., Light, M. E., Finnie, J. F., and Van Staden, J. (2010). Anti-inflammatory, acetylcholinesterase, antioxidant and phytochemical properties of medicinal plants used for pain related ailments in South Africa. J. Ethnopharmacol. 127, 235-241. doi: 10.1016/j.jep.2009.11.015 be used for the treatment of bacterial ailments in traditional medicine.

\section{CONCLUSION}

Pharmacological investigations were conducted to confirm acetylcholinesterase (AChE) and antibacterial activities of in vitro adventitious roots and ex vitro-acclimatized plants of $M$. whitei. The bioactivity was found to vary with specific concentration and combinations of PGRs during the in vitro phases. Established in vitro plants had stronger bioactivity and ability to function as inhibitors of acetylcholinesterase and antibacterial agents and thus offer potential for use as potent bioresources in traditional medicine and other commercial applications.

\section{AUTHOR CONTRIBUTIONS}

$\mathrm{PB}$ and JVS contributed in perceiving and designing the study. $\mathrm{PB}, \mathrm{AK}$, and $\mathrm{BN}$ equally contributed with experiments and collection of data for the study. Data analysis and draft of the manuscript were completed by all authors. All the authors approved the content of the manuscript.

\section{ACKNOWLEDGMENTS}

The financial support by National Research Foundation (NRF), Pretoria and the University of KwaZulu-Natal, Pietermaritzburg is gratefully acknowledged.

García-Pérez, E., Gutiérrez-Uribe, J. A., and García-Lara, S. (2012). Luteolin content and antioxidant activity in micropropagated plants of Poliomintha glabrescens (Gray). Plant Cell Tissue Organ Cult. 108, 521-527. doi: 10.1007/s11240-011-0055-z

Gelfand, M., Mavi, S., Drummond, R. B., and Ndemera, B. (1985). The Traditional Medical Practitioner in Zimbabwe. Gweru: Mambo Press.

Hahn, E. J., Kim, Y. S., Yu, K. W., Jeong, C. S., and Paek, K. Y. (2003). Adventitious root cultures of Panax gingeng and ginsenoside production through large-scale bioreactor system. J. Plant Biotechnol. 5, 1-6.

Ho, C. W., Lin, R. D., Lee, T. H., Lin, C. H., Wen, C. L., Tseng, Y. T., et al. (2013). Chemical and pharmacological investigation of micropropagated Hygrophila pogonocalyx produced from leaf explants. Bot. Stud. 54:51. doi: 10.1186/19993110-54-51

Murashige, T., and Skoog, F. (1962). A revised medium for rapid growth and bio assays with tobacco tissue cultures. Physiol. Plant. 15, 473-497. doi: 10.1111/j.1399-3054.1962.tb08052.x

Nagarajan, A., Arivalagan, U., and Rajagurua, P. (2011). In vitro root induction and studies on antibacterial activity of root extract of Costus igneus on clinically important human pathogens. J. Microbiol. Biotechnol. Res. 1, 67-76.

Noumi, E., Amvam, Z. P. H., and Lontsi, D. (1998). Aphrodisiac plants used in Cameroon. Fitoterapia 69, 125-134.

Oketch-Rabah, H. A. (2012). Mondia whitei, a medicinal plant from Africa with aphrodisiac and antidepressant properties: a review. J. Diet. Suppl. 9, 272-284. doi: 10.3109/19390211.2012.726704

Pohanka, M., Hrabinova, M., Kuca, K., and Simonato, J. P. (2011). Assessment of acetylcholinesterase activity using indoxylacetate and comparison with the standard Ellman's Method. Int. J. Mol. Sci. 12, 2631-2640. doi: 10.3390/ijms12042631 
SANBI (2013). Data From: Statistics: Red List of South African Plants Version 2013.1. Available at: http://redlist.sanbi.org/stats.php

Steffens, B., and Rusmussen, A. (2016). The physiology of adventitious roots. Plant Physiol. 170, 603-617. doi: 10.1104/pp.15.01360

Van Wyk, B.-E. (2015). A review of commercially important African medicinal plants. J. Ethnopharmacol. 176, 118-134. doi: 10.1016/j.jep.2015. 10.031

Yu, K. W., Hahn, E. J., and Paek, K. Y. (2000). Production of adventitious ginseng roots using bioreactors. Korean J. Plant Tissue Cult. 27, 309-315.
Conflict of Interest Statement: The authors declare that the research was conducted in the absence of any commercial or financial relationships that could be construed as a potential conflict of interest.

Copyright $\odot 2016$ Baskaran, Kumari, Ncube and Van Staden. This is an open-access article distributed under the terms of the Creative Commons Attribution License (CC BY). The use, distribution or reproduction in other forums is permitted, provided the original author(s) or licensor are credited and that the original publication in this journal is cited, in accordance with accepted academic practice. No use, distribution or reproduction is permitted which does not comply with these terms. 